\title{
ANOCHE TUVE UN SUEÑO
}

\author{
Ricardo Tribín Ferro*
}

Cuando se va a escribir un artículo hay que elaborar borradores, al inicio son un verdadero desastre, se van puliendo hasta que la vanidad sumado al interés oel tiempo de cada quien, le permite pensar que lo ya plasmado es una obra de arte. En el presente caso, llevaba algunos días en ese plan, recopilaba fotos familiares, de amigos, alegrías, pesares y en fin todo aquello necesario para referirme a un ser querido y recordado con tanto afecto, quien partió de este mundo, hace ya cuatro años, en un mayo 29, dejando una sensación de tristeza y ausencia, que aún hoy es evidente.

Entrada la noche y recordando con melancolía a ese gran hermano, amigo, esposo y padre, con la única compañía del silencio aterrador de la noche, con algún esporádico ruido asustador o de alguna manera esperanzador, al tratar de creer que un ruido cualquiera pueda ser una manifestación de su presencia, ya cansado y agobiado al considerar que no sería capaz de escribir en tan cortas líneas, la vida de tan importante figura, aplacé el final de mi escrito para otra jornada; me repetía una y otra vez que no estaba exaltando sus logros, que no quería repetir la misma crónica, con palabras iguales sobre alguien que ya partió, pero sé que está entre nosotros.

Me fui a dormir y extrañamente, ya que a esta edad es bien difícil hacerlo, puse la cabeza sobre la almohada y entré en un sueño profundo, de pronto me sobresalté, mi señora me preguntó el motivo, no pude explicarle que en mi sueño estaba la cara amable de Alfonso, su sonrisa, la conocida calvicie, recordé su voz firme, serena, con sus ingeniosos e inteligentes apuntes, creo que me dijo, vea hombre no se ponga a decir cosas necias sobre mi, basta con que me recuerde mi familia, mis amigos y compañeros, el personal de los sitios donde trabajé, las leales secretarias, aquéllos que mejoraron su visión con mi trabajo y todo aquél que considere que le fui útil, se lo digo porque aquí donde me encuentro, esas vanidades no existen. No sé como describir esta sensación, quizá como un último adiós, me manifestó: quiero que narre mi entrevista con el Señor y mi posible entrada a la verdadera gloria, sobre ello sí vale la pena escribir, así

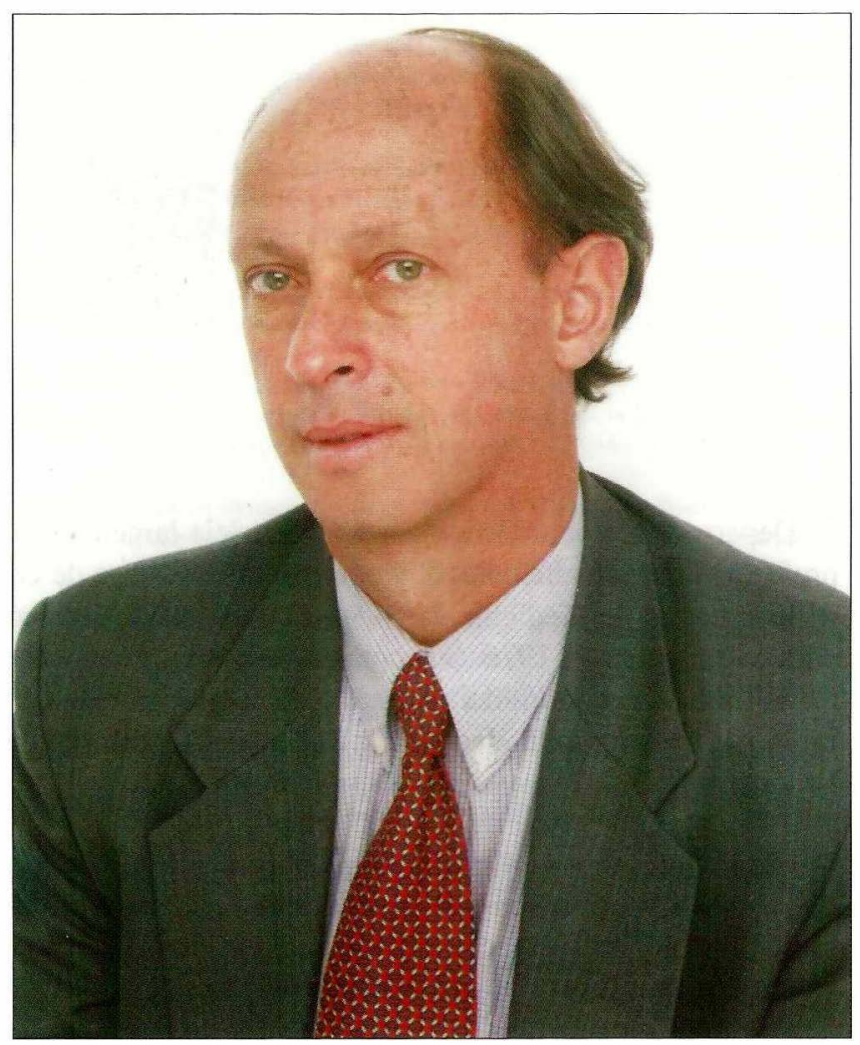

la gente entiende, de acuerdo con su verdadera conducta y sin falsedades, qué le espera.

En medio de mi sorpresa, empecé a escuchar o a imaginar lo siguiente: una persona con voz adusta le decía a Alfonso: a ver, explique qué hizo con la vida que le entregué, aquí como en el consulado de Estados Unidos sabemos todo, pero quiero oírlo de sus propios labios. Mi hermano dijo, nací en un hogar bien formado, mi padre Alfonso un médico oftalmólogo, científico muy destacado, mi madre una persona de virtudes extraordinarias de nombre Inés. Fuimos tres hermanos, dos mujeres, una de ellas médica, Ana Mercedes, otra, Inés, ama de casa y un leguleyo, Ricardo; prosiga... estudié en el Colegio Helvetia y el Refous, luego en el Colegio Ramírez, la voz le pregunta ¿dónde?, el responde en el Ramírez, era una Academia Militar para varones, allí hasta un ex presidente estudió y el Rector era un

* Coordinador del Programa de Derecho Médico. Fundación Universitaria de Ciencias de la Salud. Bogotá DC. Colombia. 
reconocido educador, Santos María Pinzón Niño; fui bachiller del Leonardo Da Vinci. Me gradué de médico del Rosario, para la época existía un convenio entre la universidad mencionada y la Sociedad de Cirugía de Bogotá, mi padre Alfonso Tribín Piedrahíta tuvo mucho que ver con él, hice mi residencia en oftalmología en el Hospital de San José. Me casé con Marcela Gómez Cortázar, quien era mi vecina de barrio, tuvimos dos hijos, a quienes en un acto insólito de originalidad, le pusimos a la niña el nombre de Marcela y al niño Alfonso, trabajé toda mi vida en mi profesión, el hospital fue mi segunda casa, en los lugares que laboré tuve grandes amigos y compañeros, procuré hacer el bien con los defectos propios del ser humano, mi vida familiar era buena, una señora destacada y unos hijos ejemplares, ellos casaron bien, con Diego y Liza, ya hasta tres nietos tengo.

En lo profesional, fui miembro de la Sociedad de Cirugía de Bogotá, Decano en las facultades de Medicina del Rosario y de la Fundación Universitaria de Ciencias de la Salud, Vicerrector académico de la FUCS, trabajé en la Universidad El Bosque y en el Hospital Simón Bolívar. Fui colegial de la Universidad del Rosario, máxima distinción que un alumno o egresado de allí pueda obtener. Escucho que el Señor lo interrumpe y pregunta ¿por qué esa molestia con su hermano el día de la misa de su fallecimiento relacionada con la Universidad del Bosque? Ay Dios mío, es que esa joyita, fue tan imbécil que ni la mencionó para dar las gracias, allí se portaron, también, muy bien conmigo, es mucho "torpe". Perdón, interviene san Pedro, puede que lo sea, pero no lo diga. Fui un buen deportista, alcancé a jugar en Millonarios en la rama profesional, tenía una zurda prodigiosa, esa pasión por el fútbol y por ese equipo era desbordante, pero esos "tullidos" no volvieron a ser campeones, qué iban a serlo con Edgar Muñoz de ortopedista de esos troncos.

El Señor le dijo a Alfonso, mire hasta aquí llega su vida material, por ello si tiene un reclamo o quiere saber alguna noticia de la tierra, pregunte y se lo contamos, después de entrar, ya nada se vuelve a saber, Alfonso preguntó ¿por qué? Mijo se imagina a todas estas almas del cielo lagarteando por sus seres queridos para que les ayude en la tierra, me vuelvo loco y no quiero ir a dónde Taborda. Por ahí debe haber una bandita que alguna información filtra, pero estamos investigando, para acabarla. ¿Quiere decir que hay chuzadas? Sí, así es, el Creador al parecer mira a san Pedro y lo recrimina, por favor chuzadas no es con $\mathrm{x}$ es con $\mathrm{z}$, caramba se parece a algunos estudiantes de la FUCS de décimo semestre, san Pedro pide excusas y como ellos se limita a decir "qué pena".

Alfonso continúa. Dios mío, me hubiese gustado vivir unos diez años más, creo que de pronto mi carrera la habría coronado como Rector de la Universidad. Dios se ríe, mi hermano al creer que se está burlando, le indaga por la razón del sarcasmo, mijito ese Jaramillo no sé de qué material lo hice, pero está enterito, le hubiese tocado esperar muchos más años. Si quiere, así se le paren los pelos del bigote, hablo con el Pichón Gómez y que lo nombre a usted Rector Honorario o algo parecido, allí creo el Doctor Cadena, Ceballos, Parra y demás miembros pueden aceptar eso, entre otras cosas porqué no genera honorarios. Es bueno contarle que en la FUCS por determinación de la Sociedad de Cirugía de Bogotá y de las autoridades universitarias, un edificio lleva su nombre, eso es un gran honor. En la ceremonia asistió su familia y se sintió muy honrada y agradecida, por fortuna no dejaron hablar a su hermano, habló Alfonso Jr. y le hizo un gran homenaje presentando un video bien elaborado, con un resumen de su vida.

Ah, debo contarle algo desagradable, su hijo se retiró del hospital, parece que se peleó con un doctor algo intransigente, al que creo le dicen la "estampa" DíazGranados, claro que el muchacho también tiene su genio, yo traté de evitar esa enojosa situación, pero no fue posible y si no ocurre algo extraordinario o algún amigo de verdad interviene, eso le va a impedir ser miembro de dicha sociedad. Allí se me vino a la cabeza la bella y magistral copla, con esta metáfora sutil y certera " $E l$ amigo verdadero ha de ser como la sangre: acude siempre a la herida sin que ninguno la llame".

Bueno, ya es suficiente, le damos la visa de entrada al cielo, despídase de una vez por todas del mundo, de sus vicios, vanidades, agradecimientos, rencores o engaños, aquí eso no existe, la felicidad no lo permite, vea a su padre y a su madre, goce con ellos eternamente y sobre el trapo azul que trae déjelo en el escritorio donde está escribiendo san Pedro. Una última anotación, Millonarios hubiese podido ser campeón, les faltó rezar más, ya que con esos jugadores, con sólo futbol era imposible ganar, además Muñoz, su amigo, sigue siendo el médico del equipo y ahora es el Vicerrector Académico. Me desperté sobresaltado, angustiado y sólo atiné a decirle a mi señora: "anoche tuve un sueño". 